\title{
Un primer acercamiento a la censura en el repertorio teatral catalán en el Archivo General de la Administración
}

\author{
ÓsCAR Fernández PoZa (UCM) \\ oskarfp20@hotmail.com \\ Recibido: marzo del 2011. Aceptado: junio del 2011.
}

\begin{abstract}
Resumen: Revisión de informes de censura conservados en el Archivo General de la Administración sobre autores y títulos representativos de la evolución del teatro catalán entre finales del siglo XIX y primera mitad del siglo XX. Criterios de censura y niveles de recepción.
\end{abstract}

Palabras claves: Teatro catalán contemporáneo y censura de posguerra. Àngel Guimerà. Santiago Rusiñol. Avel·lí Artís. Josep M. de Sagarra.

\begin{abstract}
Review reports of censorship kept in the General Archive of the Administration on authors and titles that represent the evolution of Catalan theater from the late nineteenth and first half of the twentieth century. Criteria of censorship and reception levels.
\end{abstract}

Key words: Contemporary Catalan Theatre and postwar censorship. Àngel Guimerà. Santiago Rusiñol. Avel·lí Artís. Josep M. de Sagarra.

\section{CENSURA Y LETRAS CATALANAS}

Ante el análisis formal de la censura teatral a través del tratamiento merecido por una serie de obras que pueden resultar representativas de un ciclo histórico, comenzaremos presentando el corpus de fuentes primarias —obras elegidas y sus respectivos expedientes censores-, punto seguido de una aproximación a las fuentes de estudio esenciales para abordar el impacto de la censura durante el periodo inmediato a la Guerra Civil sobre la producción teatral catalana.

\section{1. Fuentes Primarias: corpus literario y expedientes del AGA}

Partiendo de los fondos existentes en el Archivo General de la Administración (AGA, Alcalá de Henares, Madrid), realizamos un primer acercamiento a la 
censura sufrida por los escritores catalanes de teatro durante las tres primeras décadas de la Dictadura Franquista (1940-1964). Podemos indicar que en las décadas posteriores, hasta los primeros años de la Transición, las solicitudes de representación que existen y por lo tanto sus correspondientes expedientes, en la mayoría de los casos, son meros trámites firmados y, como tal, ya no suelen contener informes de lectura.

Para esta labor, hemos utilizado las secciones existentes en el citado fondo del AGA: el de Censura de Teatro y el de Censura de Libros. El primero de ellos, es el compuesto por los expedientes que corresponden a las solicitudes de las compañías teatrales o a las de los directores de estas ante las autoridades franquistas para la representación. Y el segundo, es el compuesto por los expedientes de solicitudes para la importación o la publicación de los libros por parte de las editoriales.

Actuando con criterio selectivo y eligiendo un material que entendemos como representativo histórico-literariamente, realizaremos tres calas en el avance del teatro catalán, pensando en cuatro representantes del periodo abordado. En la primera de esas calas, nos centraremos en una de las figuras de la Renaixença catalana y que ya formaba parte de los repertorios de teatro contemporáneo en catalán y en castellano desde finales del siglo XIX, Ângel Guimerà (18451924); y en especial, en su trilogía dramática formada por Terra baixa (1897), Maria Rosa (1894) y Mar i cel (1888).

La segunda, sería una doble incursión entre finales del siglo XIX y el primer tercio del siglo XX, Modernisme y Noucentisme. De Santiago Rusiñol (18611931) — una de las figuras más destacadas del Modernisme catalán y así mismo tempranamente incorporado a la escena española $-{ }^{1}$ hemos elegido dos de sus obras, de entre las que se encuentran documentadas en el AGA, El pati blau (1903) y El mistic (1903). Y por otro lado, nos fijamos en una de los autores más populares de la escena catalana del momento, seguramente con menos repercusión estatal, Avel-lí Artís Balaguer (1881-1954) quien, por diversos motivos no tuvo proyección dramática tras la Guerra Civil, a causa de dos factores importantes, el exilio y sus convicciones literarias. Artís decidió no escribir más obras teatrales y se centró en otros dos de sus puntales vitales, como impresor y como director de revistas. Pero habría que pensar que su éxito en los escenarios catalanes debería de seguir, en cierta manera, intacto, siendo todavía representado. Cabe apreciar que, durante la dictadura, no se mantuvo el peso que podría corresponderse con su éxito anterior. Solo tenemos constancia de tres expedientes, correspondientes a obras de su extensa producción teatral, no siendo estas las más representativas de la misma: Matí de festa (1910), Seny i amor, amo $i$ senyor (1925) y Isabel Cortès, Vda. de Pujol (1928).

Por último abordaremos la obra de Josep Maria de Sagarra (1894-1961), autor de preguerra y con reconocimiento catalán de crítica y público, y con éxito de alcance español ya en posguerra. En este caso hemos elegido una de sus obras

${ }^{1}$ Para la difusión y las traducciones de alcance estatal español, tanto de A. Guimerà como de S. Rusiñol, véase J. Martori (1995) y Ribera (2003: 2953-2970). 
más importantes de este periodo, La ferida lluminosa (1954), que en un primer momento habíamos pensado que iba a ser problemática a la hora de pasar la lectura, pero tras la consulta del expediente no hemos encontrado nada destacable. Aún así y en caso como este optamos por presentar el expediente, recogiendo lo que se dice en él por parte de las autoridades que lo firman.

\subsection{Presentación del informe del lector}

Dada la relevancia concedida por nuestra parte al informe del lector, como componente primordial contenido en cada expediente, informamos específicamente el tratamiento que le hemos dado. Es fácil comprender que es en los respectivos informes donde caben noticias y criterios de más enjundia.

Ante la lectura y el análisis de los informes, observamos que se pueden establecer dos partes fundamentales, una analítica y otra pragmática. La parte analítica estaría formada por los apartados establecidos en los propios impresos: argumento de la obra (Breve exposición del argumento), criterios históricos-literarios (Tesis, Valor puramente literario y Valor teatral) y criterios ideológicos (Matiz político y Matiz religioso). El primer punto es obvio y no necesita mayor explicación de su contenido. En él se cuenta el argumento con mejor o peor fortuna, con un estilo más directo y escueto o más profuso en detalles. El segundo punto lo hemos denominado nosotros así, criterios históricos-literarios, entendiendo por tal aquellos donde el lector refleja sus conocimientos literarios respecto del autor y del género que informa. Y por último, hablamos de criterios ideológicos cuando se expresan los reparos que pueda suscitar la obra en términos políticos, morales y religiosos; estos, en cierta medida, se entrelazan con la parte pragmática, como podremos ver.

La parte pragmática, por su parte, la conformarían aquellos aspectos que afectan a la hora de la representación o no representación de la obra o de su publicación. Esta parte estaría formada por los siguientes puntos: Juicio general que merece al censor, Posibilidad de su representación, Tachaduras, ¿Se juzga la obra tolerable o recomendable para menores? y Otras observaciones del censor.

\subsection{Fuentes Secundarias}

En cuanto a las fuentes secundarias encontramos varios estudios referidos a la materia, abarcando todo el territorio español o más específicamente tratando el espectro socio-cultural catalán. Coincidiendo con los inicios de la transición, aparecen obras generales de referencia como la de Antonio Beneyto, Censura y política en los escritores españoles [Barcelona, Plaza \& Janés, 1977]; o más especificas para el ámbito catalán, como es el caso del estudio de Maria Josepa Gallofré i Virgili, L'edició catalana i la censura franquista (1939-1951) [Barcelona, Publicacions de l'Abadia de Montserrat, 1991] o la obra conjunta dirigida por Josep Maria Solé Sabaté, El franquisme a Catalunya (1939-1977,) y en especial el volumen quinto, La repressió franquista (1938-1977) [Barcelona, 
Edicions 62, 2006]. El conjunto de estas documentadas monografías es esencial para contextualizar la documentación que revisaremos y para saber apreciar sus contenidos.

De entre los estudios centrados en la censura teatral, destacamos el de Berta Muñoz Cáliz Expedientes de la censura teatral franquista [Madrid, Fundación Universitaria Española, 2006, 2 vols.]. Nos interesa en particular porque recoge los diferentes expedientes teatrales de dramaturgos castellanos, como los referentes a la obra de Antonio Buero Vallejo. El tratamiento que la autora da a estos documentos nos ha servido de orientación a la hora de encarar los informes rescatados por nuestra parte.

\section{ANÁLISIS FORMAL DEL CORPUS}

Para una mayor comodidad en el desarrollo de nuestro trabajo, hemos optado por presentar a cada autor independientemente $y$, a su vez, cada una de sus obras. Estas unidades autónomas no presentan relaciones con las demás, en un primer nivel de estudio. Pero realmente, en un segundo nivel, más global, las posibles relaciones que se establezcan en lo censurado sobre los diversos autores y obras, sí que debería repercutir a favor de un acercamiento al tema general de estudio, el de la censura teatral sufrida por la producción catalana.

Cabe explicar, respecto de las páginas siguientes y a propósito de la ordenación de sus contenidos, que en dos casos - Àngel Guimerà y Josep M. de Sagarra - ha habido que ordenar el material consultado, atendiendo a una doble cláusula, pues hay informes provenientes del Archivo Censura Teatral y Archivo Censura Libro. Esto y atendiendo al caso de Àngel Guimerà, solo ante una de sus obras, Terra baixa.

\section{1. Àngel Guimerà}

\section{- Terra baixa}

a) Archivo Censura Teatral: (73/08201-717/40); (73/08718-465/46)

La primera representación de una obra de Àngel Guimerà en España, después de la Guerra Civil, es la de Terra baixa en castellano, siguiendo la traducción canónica de José de Echegaray. El 12 de febrero de 1940 Felipe García Riezu, como «exige la orden de 15 de julio de 1939 y disposiciones complementarias para la representación», solicita a favor de ésta el correspondiente permiso. Aparecen todos los trámites en el expediente 717/40 y, a su vez, otras tres solicitudes de diversas compañías, como la de Juan Santacana o la de Jaime Borrás ${ }^{2}$. En este expediente no existe constancia de que se hiciera un informe previo de un lector a la concesión definitiva del permiso.

${ }^{2}$ Los nombres de los actores y escritores catalanes que aparecen en las solicitudes, están casi siempre castellanizados. Se mantiene la grafía de los documentos. 
Habrá que esperar hasta 1946 para encontrar una primera solicitud para su representación en catalán. Recuérdese, a partir de ahora, que esa fecha actúa como umbral tanto para solicitudes como para representaciones y ediciones de teatro catalán en la lengua original. Lo veremos también en el caso inmediato de Maria Rosa y en todo caso este dato evidencia que las representaciones de teatro catalán, en caso de ser permitidas, primero lo fueron en castellano. Volviendo sobre la primera solicitud a favor de Terra baixa, para ser representada en catalán, está se conserva en el expediente 465/46. Esta es elevada a estudio por José Clavera, el 30 de abril de 1946, a favor de la compañía que tenía en sociedad con Jaime Borrás. La obra iba a ser representada entre los días 10 de mayo y 16 de junio en el Teatro Apolo de Barcelona. La compañía contaba entre sus filas con los actores, José Clavera, Jaime Borrás, Juan Estivill, Juan Xuclá, Encarnación Sánchez...

En este caso sí poseemos el informe del lector con fecha de 15 de junio de 1946, firmado por Sebastián Sánchez Juan, de la Delegación de Barcelona. En dicho informe, lo más destacable es la tachadura propuesta, ya que la Breve exposición del argumento es simple y no tiene mayor interés. En cambio, el lector propone una supresión, a propósito de una expresión de Pepa del acto I, escena 6: «i... dallonses», que el informador puede haber interpretado como un término malsonante y que, además, veremos repetida en un informe posterior, en la solicitud del mismo año acerca de la reimpresión del libro en catalán.

Un mes más tarde, Antonio Álvarez Yoart, jefe accidental de la Obra Sindical «Educación y Descanso» de Tarragona, solicita en la Delegación Provincial «...la oportuna autorización» para «...efectuar por medio del cuadro escénico de esta Obra Sindical varias representaciones de la obra 'Terra baixa' de Angel Guimera». Este segundo informe, del lector de la Delegación de la Diputación de Tarragona, es más extenso y más preciso que el anteriormente citado. Comprobamos, además, la mejor formación literaria que debía de tener este lector para realizar los informes requeridos. Encontramos consideraciones literarias que pudiera realizar un crítico literario, cercanas a un pequeño ensayo sobre la obra. Nos permitimos opinar que, aunque dicho informe no aparece firmado, tanto por fechas como por el estilo y el alcance de las apreciaciones literarias, hay otros informes que pueden deberse al mismo autor.

En el nivel analítico de este informe, la parte correspondiente al argumento es extensa en detalles, presentando más que suficientemente la obra. En el apartado de criterios histórico-literarios presenta la obra como una de los mejores dramas de la literatura catalana y en unas pocas palabras la define como:

En primer lugar se pretende recriminar la actitud del «hereu» que se cree, y es considerado, como señor y dueño de vidas y haciendas. La obra tiene un cierto sabor naturalista, al representar al hombre aislado como superior a los que viven en sociedad.

Esa idea ya la maneja al tratar el argumento, desarrollándola en la parte pragmática hacia la vertiente político-ideológica, como después veremos. Por último, en los criterios ideológicos, el lector no encuentra ningún reparo, incluso 
ve con buenos ojos las ideas que se desarrollan ya que son educativas y «exaltan la piedad del pueblo catalán»

En un primer momento, con la lectura que llevamos realizada del informe, pensaríamos que no se encontraría ningún reproche y/o reparo a la representación de la obra; aunque en el apartado Matiz religioso se habla de que la «...ortodoxia es algo discutible, pues quizás se presta a interpretar una justificación del deseo de venganza y del asesinato en defensa de la honra». Y en el punto del Juicio general que merece al censor, primer elemento del nivel pragmático, vuelve a marcar la desautorización por cuestiones de orden moral:

...la eleva hacia planos superiores, en que el público normal, no puede resultar perjudicado por su representación. Dicho público. Verá la hombría salvaje de Manelich (figura que ha merecido monumentos), admirará el sincero arrepentimiento de Marta, y difícilmente entrará en disquisiciones sobre la legitimidad del asesinato de Sebastián.

Teniendo en cuenta estas disquisiciones morales, el veredicto final del expediente es favorable para su representación sin ningún tipo de restricciones por tres causas:

- porque existen otras obras en el teatro castellano con «...dudosa tesis moral» y que no han sufrido ningún traba para su representación; el lector hace referencia, por ejemplo a las obras de Jacinto Benavente;

— porque las posibles tachaduras «...no serían capaces de variar la idea del drama, y el lenguaje es siempre decoroso»;

- y porque la obra «... no tiene ningún matiz o tendencia separatista y mucho menos antiespañola. Sin embargo, el hecho de que haya sido prohibida su representación [durante la Dictadura], ha tejido alrededor de ella una aureola de símbolo de representar con los valores morales de la 'payesía' catalana»; entendemos, por una parte, que el texto se refiere a la Dictadura de Primo de Rivera $y$, por otra, que con el presente permiso se ayudaba a desmitificar ese imaginario de alcance nacionalista.

b) Archivo Censura Libro (21/07536-6548/44); (21/08302-2503/48); (21/07920-5690/46) (21/07904-5099)

En cuanto a los expedientes correspondientes a la edición impresa, encontramos cuatro solicitudes, dos para importar la edición en castellano, correspondientes a la editorial Poseidon de Buenos Aires y dos favorables para la reimpresión en catalán.

Respecto a las ediciones de origen argentino, una es autorizada el 20 de noviembre de 1944, solicitada por la Sociedad General Española de Librería S. A. (6448/44); y la otra solicitud para la importación de la misma edición, del 28 de mayo de 1948, está firmada por Joaquin de Oteyza y Garcia. En ambas solicitudes no se encuentra ninguna tachadura con propuestas de supresiones en el texto.

En el caso de la edición en catalán, tenemos que esperar dos años más, hasta septiembre de 1946, cuando se solicita el permiso por parte de Adriana y 
Sara Aldavert, de AS Aldavert. En el informe del lector, se indica que se autoriza la publicación siguiendo las directrices ya dadas desde la Dirección General de Cinematografía y Teatro, con tachadura en la página 10: «y... dallonsas...» (acto I, escena VI). Y a finales de ese mismo año, Antonio Martínez Tomás, solicita la reimpresión en catalán para la edición de Ediciones Mercedes de Barcelona, volviendo el censor a indicar la misma tachadura.

- Maria Rosa (73/08401-2994/42); (73/08715-428/46)

La primera solicitud —como todas las referentes a esta obra, provenientes únicamente del Archivo Censura Teatral- para representar la obra en la traducción castellana de José de Echegaray, es del 16 de marzo de 1942. Solicitada por Constantino Baquer Carraras, representante de la compañía de Anita Adamuz y Alfonso Muñoz, generará el expediente 2994/42, que será utilizado para las posteriores solicitudes de las representaciones siguientes. Según nos consta fueron de casi una veintena durante el periodo de 1942 a 1969. De dicho expediente solo merece la pena destacar, por una parte, el juicio moral que la obra le merece al lector:

... no puede autorizarse la obra, drama trágico pasional que culmina en un homicidio. Pero dentro de ello y dado caso que el espectador puede discernir suficientemente lo malo de lo bueno y como obra literaria de estudio psicológico de tipos y de ambiente, puede tolerarse.

Así mismo, por otra, las tachaduras propuestas para la supresión y que suelen ser de alcance social y constitucional: nunca».

— p. 21: «Pero yo digo... echa el dinero?»; «En la Diputación no aparece

— p. 39: «Compañeros».

— pp. 40-41: «Cuando nos viésemos allí... es hablar no sabemos...».

— p. 50: «iEs que desde allá... me atormenta!».

— p. 57: «y revolcándose fiebroso... el resuello»; «con la cabeza me doy de golpes en ella».

En cuanto a las solicitudes para su representación en catalán, habrá que volver a esperar hasta el año antes mencionado. El 30 de abril de 1946 se tiene constancia de una primera solicitud. La realiza Juan Tuset Bonet en Tarragona, director de la Agrupación Teatral de Aficionados «Elenco de la Comedia». En un escrito de 19 de junio del mismo año, aparece la confirmación de la autorización de la representación de la obra. El expediente 428/46, donde aparece toda esa información, está compuesto por tres informes de lectores diferentes: por José $\mathrm{M}^{\mathrm{a}}$ Malagelada (Barcelona, 12-06-46), por el lector de la Delegación Provincial de Tarragona, sin firma (21-06-46) y por un tercero el cual no llegamos a identificar el nombre, a causa de la letra (Madrid, 11-07-46).

Tanto del informe de Malagelada como del informe de Madrid, no hay nada que destacar ya que la mitad de los campos que debían rellenar los lectores 
en el informe no se encuentran desarrollados, excepto el del argumento y el del juicio del censor. Resulta curiosa la no coincidencia en su criterio a la hora de calificar la obra. Mientras Malagelada la considera «...como una de las mejores obras dramáticas en catalán», en el caso del informe de Madrid no se eleva a tal categoría la obra de Guimerà, ya que sólo le parece «...uno de tantos dramas románticos rurales del autor. No es 'Tierra baja' pero en algunos pasajes acierta con éxito seguro. El final tiene grandeza trágica»

En el tercer informe señalado, el del lector de la Delegación Provincial de Tarragona, este lector, coincidiendo con un informe de entre los comentados sobre Terra baixa (poner $n .^{\circ}$ exp. Y fecha de este), ofrece unos juicios elaborados y cercanos a la crítica literaria, como indicamos en aquel caso. Ahora, destacan los apartados correspondientes a los criterios históricos-literarios. Este informe es mucho más crítico que los dos anteriores a propósito de Maria Rosa. No utiliza los términos de los otros dos lectores: califica su prosa como perteneciente «...a los últimos tiempos de la 'Renaixença' catalana, y como es natural presenta un léxico no completamente evolucionado, con ortografía y giros hoy en desuso»; en el campo Valor teatral, califica la obra como «...tragedia muy sentimentalona, a propósito para públicos no muy educados ni exigentes; de recursos escénicos pobres y con notables defectos». Aún así, la valora positivamente, remarcando de nuevo, como ya habíamos visto en mencionado informe acerca de Terra baixa, la atención al alcance de la figura de los payeses y su representación en el teatro de Guimerà:

Esto último, es una enorme ventaja para representaciones en los pueblos de Cataluña, puesto que en ellos — dejando aparte consideraciones de orden político — la dificultad para popularizar el teatro castellano, no reside actualmente, tanto en el lenguaje como en el divorcio de sentimientos y costumbres entre público y autor.

Cuando el lector de Tarragona encara la parte pragmática del informe, vuelve a ser duro con la obra. En su juicio como censor, indica las pautas que se debían seguir a la hora de ser representada y prohíbe su representación por elencos de aficionados porque no se puede controlar la entrada de menores al espectáculo; pero, sí es autorizada para compañías profesionales donde sí se puede prever la entrada del público de acuerdo con su edad. Las causas de esta diferenciación son por el lenguaje empleado y por las violentas pasiones representadas. De acuerdo con esto, cabría pensar que habría un mayor número de tachaduras recomendadas en el texto pero solo propone dos $^{3}$, coincidentes en el componente sexual:

— suprimir el relato de Maria Rosa de la página 22: «Y's ficá al llit ab mi, y no's va moure del meu costat, nó!»;

- suprimir la siguiente frase del relato del sueño de Maria Rosa de la página 55: «y que'l tenia al 1lit, al meu costat, all lloch del Andreu, y...»

${ }^{3}$ Siempre según la 5. edición de la obra impresa por la Imprenta La Renaixensa, como indica el censor 


\section{— La filla del Mar (73/08757-97/47)}

En este caso solo tenemos solicitudes para su representación en catalán en tres momentos diferentes, recogidas conjuntamente en el expediente 97/47. La primera, y como en las otras dos obras de Guimerà, corresponde a 1946, momento de una pequeña apertura tras la victoria de los aliados en la II Guerra Mundial ${ }^{4}$ o por la actitud más tolerable del nuevo gobernador civil de Barcelona, Bartolomé Barba Hernández 5 . Las otras dos ya corresponden al primer lustro de la década de los sesenta.

En el informe censor del 9 de julio de 1946, realizado por José María Malagelada Mir, destaca la parte pragmática del informe. En ella se propone la prohibición de su representación, pero, por ser quien es el autor, «...el censor cree debe abstenerse de clasificarla y dejar que sea la Superioridad quien, con mejores conocimientos, pueda decidir si se autoriza o no su representación». En el expediente sobre la solicitud no se encuentra ningún oficio que indique cual fue la resolución tomada. Malagelada propone las siguientes tachaduras:

- página 83: en un parlamento de Catarina: «el bon Jesus»;

— página 133: en un parlamento de Pere Martir: «De la terra, del cel, de per tot a tu sola, a tu sola!»

El 1 de septiembre de 1961 Mario Cabré solicita el permiso para la representación de la obra, realizando el informe censor Javier de Valdivia, el 11 del mismo mes. Este informe es mucho más duro a la hora de calificarla, tanto en las tachaduras como en las supresiones «recomendadas». A propósito del Matiz religioso, se califica la obra de peligrosa por el tema tratado.

Mediante las tachaduras propuestas, como indica el propio censor, se «tiende a corregir la crudeza» de alguna de las escenas, como la final (pp. 149-1506) o la escena de la pelea entre Agata y Pere Martir (p. 140). Pero en el ejemplar utilizado para la lectura, en su portada, encontramos más tachaduras que las propuestas en el informe censor. En definitiva estas son:

— Acto II, escena XI, pp. 102-103: «Quan al poble's.... que os féssiu» Se encuentra recuadrado a lápiz; escena XVII, p. 115: «A jeure! A jeure! (suprimido)».

— Acto III, escena I, pp. 119-120: «Qué credi tothom!... Companys: visca'l més guapa del poble» Se encuentra recuadrado a lápiz; escena I, p. 120: «Ja no’n podia ser... no respecta cap dona!» Se encuentra recuadrado a lápiz; escena I, p.

4 Benet (1995: 378)

5 Extraído el texto de J. Benet, op. cit., que remite a Barba (1948: 28), donde leemos: «Otro avance en este sentido lo constituyó la reposición de las obras teatrales de la literatura catalana. Al efecto, el director general de Cinematografía y Teatro me comunicó que autorizaba las representaciones en lengua catalana siempre que se cubriesen los trámites reglamentarios establecidos con carácter general para toda clase de representaciones»

${ }^{6}$ Estas páginas corresponden a la edición utilizada para la lectura del censor, que es la debida a la Imprenta de la Renaixença. 
121: «Quan vulgas me trobarás á fora... .Ara mateix! Aém!» Se encuentra recuadrado a lápiz; escena II, pp. 121-122: «Gregori: á dintre... Sogre!» Se encuentra recuadrado a lápiz; escena II, p. 122: «Si: que l'hem... que'es mentida!» Se encuentra recuadrado a lápiz; escena II, p. 123: «Nó! Per la Mariona nó!... (En Pere Martir s'hi va á tirar al damunt)» Se encuentra recuadrado a lápiz; escena II, p. 123: «Perqué fa pilladas!... á l'Agata!» Se encuentra recuadrado a lápiz; escena III, p. 124: «Donchs jo no't... Veus, dona?» Se encuentra recuadrado a lápiz; escena VI, pp. 131-132: «Ab aquesta ni'ns hem... Ja us ho dit: que no sé res.» Se encuentra recuadrado a lápiz; escena IX, pp. 140: «(Cauhem els dos ballantse damunt de la sorra)» Suprimido; escena XII, p. 148: «tod del mon y del cel» Suprimido; escena XII, pp. 149-150: Final suprimido y reemplazado por:

Agata:

Ahi

(Cridant-lo com boja)

Pere Martir!

(Se sente repicar un instant $i$ al lluny, les campanes.)

Balta.

Y toca per vostre casament!...

Agata:

(Plorant amb rábia)

Y jo l'he mort! Jo l'he mort!

(Ab crit fort, encarant-se amb la Mariona, plorant rabiosa)

A, nó! Pere Martir!

Mariona:

Heretje! Mala sanc. Si, si: l'has mort tu mateixa!

Agat:

$\mathrm{Si}$, si; jo, si. Y al matarlo he quedat per sempre neu! Y tu t'has quedat una perduda

Sola, més rica; rica, si; mes dintre del or, mala dona, mala dona, mala dona!... 


\section{Mariona:}

(Sense haber-la deixat acabar)

Malagrahida que m'ho deus tot!

Agata:

No, aixó no! Mai! No vull agrairte res!...

Aparteu-vos!...

Poble:

No! Atereu-la!...

Agata:

(Fugint, corrents, amb un gran crit!)

Deiuxeume!... Malahit el dia en que em va recollir en aquesta terra. Eh!...

(Y fuig, com bojo, mentre cau el teló)

Tras la revisión del expediente, se prohíbe la representación de la obra de acuerdo con el oficio del Jefe de la Sección de Teatros y del Director General.

En marzo de 1963, de nuevo Mario Cabré pide otro permiso para la representación de la obra, realizando ahora el informe censor Juan Cirera de Luna, quien no propone ninguna pega ni tachadura para la representación de la obra. Esta decisión es refrendada por el oficio firmado por M. de Fraga de Lis, Jefe de la Sección de Licencias e Inspección, y José M. ${ }^{a}$ Ortiz, Jefe del Servicio de Teatro.

Como conclusión podemos decir que resulta curioso lo siguiente, si observamos en conjunto los tres informes de La filla del mar. Podemos apreciar una evolución o vacilación en los criterios censores, de unas pequeñas correcciones al texto en 1946, a una gran censura en el de 1961 o a la no aplicación de ninguna tachadura al informe de 1963. Así mismo, cabe advertir el matiz de las correcciones que, por su sentido, pasan por lo religioso, lo violento.

\subsection{Santiago Rusiñol}

— El mistic (73/08211-826/40); (73/08727-590/46) 
De esta obra existen tres solicitudes para su representación, dos en castellano y otra en catalán. De nuevo encontramos ante dos fechas que ya sabemos interesantes en nuestra revisión, 1940 y 1946. En 1940 (expediente 826/40), existen dos solicitudes para la representación en castellano, el 2 de marzo a cargo de Enric Borràs y el 12 de agosto por parte de Juan Santacana. Se solicita en ambas el permiso de representación para sus respectivas compañías. El informe censor no se conserva en el expediente, pero en uno de los libretos archivados están las censuras propuestas, recogidas a continuación. Apréciese que insisten en cuestiones de tipo religioso y de posible interpretación sensual:

- Acto I, escena II, p. 8: «Cristo solo fue cristo».

— Acto II, escena I p. 32: «iQué hizo!... ¿Y lo mató usted?»; escena II, p. 35: «Para eso está su hombre. ...Para ella hace.»; escena IV, p. 42: «...Me hablas como si fueses... desde la tumba» «Buscaba la mano del amigo, no la palabra del confesor.»; escena VIII, p. 46: «¿Qué dice usted.... pobre... decente»; escena VIII, p. 47: «Venga usted a la fiesta. Le esconderemos en un rincón y podrá oirlo».

- Acto III: escena VIII, pp. 68-69: «Sospeche usted de mí, de ella no.... ¿Qué mal uso hago yo?».

- Acto IV: escena IV, p. 78: (con desaliento); escena VI, p. 81: «¿Cómo has tardado tanto tiempo en venir?»; escena VI, p. 83: «No la sientes entrar en ti?»; «Soy yo que te traigo mi juventud...., una hermana que espera»; escena VIII, p. 86: «iMarta! ¿Dónde estas?».

En 1946 debió de existir un informe censor solicitud de representación en catalán pero no se conserva entre el material del expediente 590/46. Hay constancia de su existencia gracias a la solicitud de la Compañía Teatral Maria Vila-Pio Daví, del 6 de marzo de 1948.

\section{—El pati blau (73/08421-3916/42); (73/08712-386/46)}

De esta obra contamos con dos solicitudes para la representación en castellano y en catalán. El 9 de junio de 1942, Juan Aulí Padró solicita el permiso para representar en castellano la obra según la versión de Rosendo Llurba, realizando el informe censor Guillermo Reyna Madina, se genera el expediente 3196/42. No hay que realizar ninguna mención mayor sobre el informe por su brevedad, solo cabe indicar la tachadura propuesta de la página 30 , que coincide con parte de la que veremos recogida en el informe correspondiente a la representación en catalán. La supresión que se sugiere en el caso del informe castellano es más extensa, llegando hasta el final de la escena. Corresponde a dos intervenciones del Metge y Jacinto; sólo se salva, de la primera intervención del Metge la siguiente frase: «Uno sólo, el milagro». Por tanto, una vez más parece que estamos ante cuestiones de matiz religioso que se pudieran considerar irreverentes.

El 16 de mayo de 1946, la compañía Jofré-Gener solicita el permiso para dicha representación en catalán, en el Consistorio de Manresa y para la fecha del 19 de junio siguiente. Realiza el informe el censor José M. ${ }^{a}$ Malagelada Mir, el 4 de junio de aquel año. De su texto destacamos la tachadura propuesta, propo- 
niendo eliminar en la página 14, en la segunda columna, las siguientes intervenciones en la conversación entre el Metge y Jacint que cuestionan la credibilidad del mencionado milagro:

Metge: pero no hi creiem hi vós ni jo

Jacint: I qui tingues fe per a creure-hi

\subsection{Avel·lí Artís i Balaguer}

- Seny i amor, amo i senyor (73/08712-387/46)

De la producción dramática de Artís i Balaguer que hemos seleccionado y sobre la que existen expedientes en el AGA, Seny $i$ amor..., es la primera obra a favor de la que se solicita permiso para su representación. A propósito de ella aparecen tres solicitudes entre 1946 y 1967, siendo la primera la más interesante para nuestra revisión.

El 6 de mayo de 1946 la compañía Jofré-Gener solicita el permiso de representación de la obra para llevarla a cabo el 19 de mayo de 1946 en el Consistorio de Manresa. De esta solicitud deriva el expediente 387/46 de la delegación de Barcelona, firmado por el censor Juan José Permanyer Cintrón, con fecha 4 de junio de 1946. En el mismo lo más destacado son las tachaduras y las correcciones propuestas por él. En este caso la tachadura y la corrección que se proponen tienen una vez más marcado sentido religioso. La tachadura corresponde en la página $49^{7}$ (escena XIV del I acto) al nombre de «Cristo» y la corrección en la página 134 (escena XV del III acto), propone sustituir la frase «I això no hi ha Dèu que ho arregli» por «I això no hi ha qui ho arregli» ${ }^{8}$.

- Isabel Cortés, Vda. de Pujol (73/09166-261/55) y Mati de festa (73/09178-3/56)

En cuanto a estas dos obras tenemos que esperar hasta mediados de la década de los cincuenta para encontrar solicitudes para sus representaciones. Isabel Cortés, viuda de Pujol es solicitada por el Director de la Compañía Teatral Club Barcelona, como «...exige la Orden de 15 de julio de 1939 y disposiciones complementarias para representar la obra teatral titulada 'Isabel Cortés vda. de Pujol' cuyo autor y demás características se expresan», el 29 de Julio de 1955 en Palma de Mallorca. Y para Mati de festa, por el Teatro de Cámara del «Centre de Lectura de Reus», junto con la obra de Jacinto Benavente Operación Quirúrgica (exp. 2/56), para representarse durante la segunda quincena de enero de 1956.

De la lectura de ambos informes, se desprende la actitud por parte de los censores de estar realizando un proceso ya mecánico, casi un mero trámite,

${ }^{7}$ En el ejemplar presentado a la censura corresponde a la página 12.

${ }^{8}$ En el ejemplar corresponde a la página 30. 
aunque formalmente se mantienen en unos parámetros de presentación. Tengamos presente que en épocas posteriores, la cumplimentación de dichos formularios todavía será más automática. No aparece ninguna objeción a las obras, incluso cuando, por los cambios sociales a propósito de la creciente independencia femenina según se puede ver en Isabel..., el censor podía haber mostrado sus reticencias.

\subsection{Josep Maria de Sagarra}

De la producción dramática de Sagarra solo vamos a hacer referencia a su obra La ferida lluminosa, tanto a los informes censores para teatro como para su publicación dentro de volumen de IV de las Obras Completas, que recoge su producción dramática.

a) Archivo Censura Teatro (73/09136-405/54); (73/09176-359/55)

Entre los expedientes que existen en la censura sobre teatro hay dos entradas sobre la obra, de 1954 y de 1955. En diciembre de 1954 el Director de la compañía Teatral Candilejas pide la solicitud del permiso para su representación. Da lugar al expediente del censor Bartolomé Mostaza, del 4 de enero de 1955. De este informe podemos destacar dos cuestiones: en Breve exposición del argumento se destacan dos verbos que aparecen entrecomillados — «liarse» y «ver»-, y que marcan para el censor dos momentos importantes de la obra y en la evolución y posicionamiento moral de los personajes, provocando el desenlace del drama. En nuestra opinión, el verbo «liarse» y el momento de la obra a que corresponde, podría haber provocado una reacción negativa por parte del censor, ya que en la mentalidad de la época no era común ver representada la unión sentimental entre dos miembros de la misma familia. Por contraposición, el verbo «ver» — con el sentido de «entender»— le permite al autor congraciarse con la censura y los valores religiosos y sociales de la época. El personaje del padre sufre una transformación en sus valores y vuelve a la línea que marcan la doctrina y la sociedad. Por ello, en el Juicio general que merece al censor se apreciará el valor de la obra y que no debe ser prohibida su representación, con el único matiz de que se recomienda para mayores de 16 años:

Obra que posee fuerza por el argumento. Está construida sin «malicia» teatral. El diálogo es demasiado monótono, sin contrastes. Lo mejor, el final del tercer acto. El epílogo rebaja en grados la emoción del desenlace.

Moralmente, perfecta. El autor sabe bien la tesis católica del matrimonio.

El 2 diciembre de 1955 el Director de la compañía Teatral «Titular de Lara» pide la solicitud del permiso para su representación, dando lugar a dos informes de distintos censores. El primero lo firma R. P. Fray Mauricio de Begoña, el14 de diciembre de 1955. Destacamos el Juicio general que merece al censor:

La obra no ofrece particular dificultad en el orden moral y religioso; antes bien, tanto por su fondo, por su forma, tiende a la exaltación de los mencionados va- 
lores. Aunque alguna frase suelta, aisladamente considerada, pudiera suscitar algún reparo, contribuye también al afecto general de la obra que es aleccionador.

El segundo informe corresponde a Adolfo Carril, del 15 de diciembre de 1955. Como en el anterior, destacamos sus palabras del apartado pragmático del juicio general que merece al censor:

Comedia dramática de cierta altura correctamente desarrollada en cuanto a la exposición de su tesis que estimo licita y exacta desde el punto de vista moral en que está concebida (...) Creo sinceramente que están manejados con dignidad los principios católicos y no la encuentro reparos de convicción a los efectos de censura.

Los tres censores que revisan la obra de Sagarra coinciden en la misma idea a la hora de permitir su representación, la defensa de los valores religiosos y morales que se desprenden de la misma. Estos valores están en consonancia con los que defendía el nacional-catolicismo del Régimen de Franco, concretamente en este caso, el de la familia bajo la doctrina de la Iglesia Católica.

b) Archivo Censura Libro (21/15043-1163/64)

En lo que se refiere a este apartado, recuérdese que es en 1964 cuando la obra pasa a formar parte del volumen correspondiente de las Obras Completas de Sagarra. Es el expediente 1163/64 donde se sanciona esta entrada. En el oficio del Jefe Servicio de Teatro al Jefe Sección Orientación Bibliográfica se hace constar que la obra tiene una tachadura pero no puede indicar cual es, ya que no se encuentra el ejemplar de archivo. En los tres informes de los lectores que componen dicho expediente no se encuentran las referencias a la tachadura.

\section{CONCLUSIONES}

Para concluir nuestro trabajo nos plantearemos una serie de preguntas que nos surgen con este primer acercamiento al tema y a los diferentes informes de las obras. La atención tanto a las obras elegidas como a los informes suscitados por las mismas da lugar a la aparición de ese segundo nivel de relaciones entre los títulos informados y los criterios tenidos en cuenta para la censura:

a) En este segundo nivel habrá que poner en relación las unidades autónomas, que son cada una de las obras representativas seleccionadas, e intentar comprender mejor cómo funciona la censura según la naturaleza de cada una de ellas o incluso según su autoría, de orden distinto si se atiende a un clásico como Àngel Guimerà o a otro autor como Avel-lí Artís i Balaguer, que en esos momentos era un exiliado. Ese nivel global de relaciones que se establezca entre lo censurado, no solo se reflejará en el nivel analítico y pragmático, sino también en la comprensión por parte de los firmantes de los informes. 
b) Siguiendo con ese segundo nivel de relaciones, no sólo atenderíamos a las conexiones entre las obras en catalán, sino con sus correspondientes traducciones castellanas. Por ejemplo, como hemos visto en el caso de Terra baixa, en el expediente de la representaciones en castellano los censores no proponen ninguna censura; al contrario del caso en catalán, en que sí hay propuestas de tachaduras. Habría que preguntarse el por qué de este hecho, si se debería a estar escrita en catalán o porque el censor de la traducción no vio peligro alguno en ella. Pero en el caso de Maria Rosa, al contrario, es vista más peligrosa la traducción que el original catalán, por el tema abordado y por su tratamiento.

c) En cuanto a La filla del mar habría que plantearnos dos cuestiones: primero, quiénes fueron intelectualmente los censores de los años sesenta, para comprender la gran diferencia ideológica a la hora de ejecutar la censura, y por qué no se siguieron criterios coincidentes entre ellos; $y$, segundo, nos plantearíamos qué texto llegó a las manos de Juan Cirera de Luna para realizar el informe. ¿Un texto depurado por la censura previa del 61? o ¿fueron otros sus criterios a la hora de censurar y acaso no tenía los mismos problemas ideológicos que el censor del 61 ?

d) De las censuras propuestas en los diferentes expedientes se puede sacar la conclusión de que todas ellas se centran fundamentalmente en dos aspectos, lo religioso y lo socio-político, sean los informes indistintamente para las representaciones en castellano o en catalán. También suelen aparecer indicaciones que alcanzarían a la intencionalidad sensual o sexual de lo expresado en los originales censurados.

\section{BIBLIOGRAFÍA}

Barba, B. (1948) Dos años frente al Gobierno Civil de Barcelona y otros ensayos, Madrid.

Benet, J. (1995) L'intent franquista de genocidi cultural contra Catalunya, Barcelona, Publicacions de l'Abadia de Montserrat.

Martori, J. (1995) La projecció d'Àngel Guimerà a Madrid (1891-1924), Barcelona, Curial/Publicacions de l'A Abadia de Montserrat.

Ribera, J. M. (2003) «Relaciones entre los teatros contemporáneos castellano, catalán y gallego», J. Huerta Calvo (coord.) Historia del teatro español, Madrid, Editorial Gredos, vol. 2, pp. 2953-2970. 